and his collaborator, Dr. Zabel, showed how to overcome the difficulties involved, and the present series of ten highly successful coloured stereo-photographs shows that the production of such pictures has passed from the experimental stage to an established procedure. There can be no doubt that the publication of these photographs opens a new field in the illustration of eye diseases.

The principles employed in the making of these photographs are not explained in the four-page pamphlet (in German) accompanying the pictures. The author refers to the transactions of the Congress mentioned, from which it appears that the camera used is one specially constructed according to the design of Professor Wessely, and that the photographs are taken by an ordinary nitra light. But in a footnote in the present pamphlet a statement is made that some of the pictures were taken by " a small Stereo-Palmos Icacamera by the use of flashlight."

The appearance of the present collection almost immediately after the excellent series of uncoloured photographs by von Rötth (reviewed in the February number of this journal) shows that considerable attention is being given to stereo-photography in Central Europe.

\title{
CORRESPONDENCE
}

\section{IMPROVEMENT OF VISUAL ACUITY OF CATARACTOUS EYES}

\section{To the Editor of The British Journal of Ophthalmology.}

DEAR SIR,-In view of reference in this Journal in recent years to visual changes in cataract cases with or without medicinal treatment, it seemed that it might be of interest to report the following case :-

Miss H.E., aged 56 years, was seen in May, 1927. V.R. 6/18 (2 letters); V.L. 6/36. By retinoscopy and without a mydriatic, some hypermetropia and $0.25 \mathrm{D}$. astigmatism was found in the right and $0.5 \mathrm{D}$. astigmatism in the left eye.

R. $\frac{+1.5 \text { D.sph. }}{+0.25 \text { D.cyl. } 90^{\circ}}=6 / 9 . \quad$ L. $\frac{+1.0 \text { D.sph. }}{+0.50 \text { D.cyl. } 120^{\circ}}=6 / 18$.

In March, 1929, retinoscopy revealed more hypermetropic astigmatism in the right and very slightly more in the left eye.

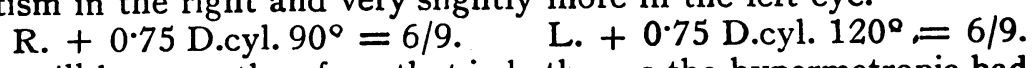

It will be seen, therefore, that in both eyes the hypermetropia had disappeared, leaving only hypermetropic astigmatism. The vision of the left eye with a cylindrical change of only $0.25 \mathrm{D}$. had improved from $6 / 18$ with a lens in 1927 to 6/9. It should be noted 
that, with the lens of 1927 , the left vision was, in 1929, as much as 6/12. Further remark or comment seems unnecessary.

Yours faithfully,

HUMPhREY NeAME.

LONDON,

Pebruary, 1930.

\section{GLAUCOMA RESEARCH}

To the Editor of The British Journal of Ophthalmology.

Sir,-It is not too soon to suggest that a discussion on glaucoma be made a main item on the programme of the next International Congress and that the International Council appoint a subcommittee to deal with the matter, with objects somewhat as follows.

1. To arrange that systematic study of different specific aspects of the subject be taken up in some half-dozen or more of the larger clinical centres and laboratories.

2. To act as a co-ordinating centre, receive interim reports and issue bulletins to the workers, so that results as they are obtained may be available to all who are actively investigating.

3. To receive all final reports, some six months before the date set for the Congress and to co-ordinate them into a general report.

So many practical suggestions, requiring investigation, have been made, that if an adequate system were organized, a large amount of information would be available, possibly even the problems of cause and treatment solved. The mere task of organization will be no light one as so many details need investigating.

What for instance is known of the type of glaucoma in which the nerve-head seems to melt away, although there is practically no uveitis nor hypertension? To me it always recalls a sarcomatous knee-joint which was exhibited at the British Medical Association meeting in 1923 at Portsmouth. This large specimen, some ten inches across, had been bisected and half of it mounted in the usual way. The other half had been submitted to the action of a broth containing bacillus subtilis and a staphylococcus. It looked as though it had been left out in the field, to the action of beetles, larvae and micro-organisms. The bone had been picked clean, within and without, there was not a vestige of soft tissue left and the various concentric layers of pathological bone stood out stark and naked and this was largely due to a staphylococcus. It may seem fanciful to think that there is any connection in the disappearance of tissue in these two instances, but there is reason to think that a staphylococcus was active in both. In $1925 \mathrm{I}$ reported a few cases in which a staphylococcus was found within the eye-ball 